05

\title{
Спектральные характеристики свечения поверхности частиц каменных углей во время воздействия лазерных импульсов в режиме свободной генерации
}

\author{
(С) Б.П. Адуев, Д.Р. Нурмухаметов, Я.В. Крафт, З.Р. Исмагилов \\ Федеральный исследовательский центр угля и углехимии Сибирского отделения РАН, \\ 650000 Кемерово, Россия \\ e-mail:lesinko-iuxm@yandex.ru
}

Поступила в редакцию 02.07.2020 г.

В окончательной редакции 02.07.2020 г.

Принята к публикации 10.08.2020 г.

Исследованы спектры свечения фракций каменных углей с размерами $d \leq 63 \mu \mathrm{m}$ непосредственно во время воздействия импульсов неодимового лазера $\left(\tau_{i}=120 \mu \mathrm{s}\right)$. В зависимости от плотности энергии излучения $H$ спектры свечения имеют различный характер. Свечение при минимальных значениях плотности энергии лазерного импульса $H_{c r}^{(1)}$ связано с зажиганием мелких частиц углей $(\sim 1 \mu \mathrm{m})$, присутствующих во фракциях, и с зажиганием реакционно активных микровыступов на поверхности более крупных частиц углей. Спектры свечения на этом этапе имеют нетепловую природу и связаны с излучением молекул летучих веществ в газовой фазе и продуктами их окисления. При повышении плотности энергии лазерного импульса $H$ наблюдается тепловое свечение поверхности более крупных частиц углей, которое описывается формулой Планка при $T=3100 \mathrm{~K}$. При достижении $H=H_{c r}^{(2)}$ происходит воспламенение поверхности частиц угля во время воздействия лазерного импульса. В спектры вносят вклады свечение поверхности частиц угля, вылетающие углеродные частицы и свечение, связанное с излучением возбужденных молекул $\mathrm{H}_{2}, \mathrm{H}_{2} \mathrm{O}, \mathrm{CO}_{2}$. При увеличении $H>H_{c r}^{(2)}$ процессы, приводящие к свечению частиц угля во время лазерного импульса, аналогичны выше описанным при $H_{c r}^{(2)}$, но возрастает интенсивность свечения.

Ключевые слова: уголь, лазер, зажигание, летучие вещества, степень углефикации, коксовый остаток.

DOI: $10.21883 /$ OS.2020.12.50327.187-20

\section{Введение}

Развитие понимания процессов зажигания и интенсификации горения твердых минеральных топлив невозможно без детального изучения начальных механизмов его воспламенения.

При исследовании начальных механизмов воспламенения углей в качестве источника зажигания может использоваться лазерное излучение. Имеется достаточно большое количество работ с использованием $\mathrm{CO}_{2-}$ и неодимовых лазеров [1-8]. Основные выводы, которые следуют из этих работ, сводятся к тому, что в результате поглощения лазерного излучения происходит нагрев поверхности частиц углей, выход и воспламенение летучих веществ в газовой фазе и зажигание нелетучего остатка. С использованием лазеров с миллисекундной длительностью импульсов изучена кинетическая зависимость свечения при зажигании частиц углей [1]. Однако детального изучения различных стадий процесса лазерного зажигания угля практически не проводилось. Такие исследования начаты в наших работах [9-11].

На примере бурого угля и каменных углей (Кузнецкий угольный бассейн, РФ): длиннопламенного газового (ДГ), газового (Г), жирного (Ж) и коксового (К) установлено, что при воздействии лазерных импульсов неодимового лазера в режиме свободной генерации $\left(\tau_{i}=120 \mu \mathrm{s}\right)$ можно выделить три стадии зажигания в различных временных интервалах, обладающих порогами воспламенения с характерными плотностями энергии $H_{c r}[10,11]$. Первую стадию зажигания, протекающую во время воздействия лазерного импульса, мы связали с нагревом поверхности частиц угля и воспламенением микровыступов на их поверхности. Вторая стадия зажигания, протекающая в миллисекундном временном интервале, связана с выходом и воспламенением летучих веществ. Третья стадия зажигания, протекающая во временном интервале $\sim 100 \mathrm{~ms}$, связана с зажиганием нелетучего остатка. Тем не менее для понимания деталей механизма зажигания необходимо последовательно изучить процессы на различных стадиях зажигания, начиная с момента воздействия лазерных импульсов. В этом плане новую информацию можно получить, используя регистрирующую аппаратуру с временным разрешением, которое позволило бы провести измерение спектров свечения, возникающих непосредственно во время воздействия лазерного импульса на частицы угля, т. е. на самых ранних этапах зажигания.

В настоящей работе проведены такие измерения с использованием частиц вышеперечисленных каменных углей при плотностях энергии лазерного излучения, соответствующих $H_{c r}$ для каждой из трех стадий зажигания. 


\section{Образцы и методика эксперимента}

В работе использовались образцы каменных углей Кузнецкого угольного бассейна, перечисленные во введении. Пороги зажигания этих углей изучены в [11]. Угли, как и в работе [11], подвергались помолу на шаровой мельнице, затем при помощи сит отбирались фракции углей с размером частиц $\leq 63 \mu \mathrm{m}$. Результаты технического анализа углей приведены в работе [11]. Использовались частицы угля с насыпной плотностью $\rho=0.5 \mathrm{~g} / \mathrm{cm}^{3}$, массой $10 \mathrm{mg}$, которые помещались в медный капсюль диаметром $5 \mathrm{~mm}$ и высотой $2 \mathrm{~mm}$.

В качестве источника излучения использовался лазер на иттрий-алюминиевом гранате с неодимом, работающий в режиме свободной генерации на длине волны $\lambda=1064 \mathrm{~nm}$, с длительностью импульса $\tau_{i}=120 \mu \mathrm{s}$ и энергией в импульсе до $W=1.5 \mathrm{~J}$. Регистрирующая аппаратура предназначена для измерения спектральнокинетических характеристик свечения частиц угля и пламени в режиме реального времени. Функциональная схема экспериментальной установки приведена и подробно описана в работе [10].

Для изучения свечения поверхности образец угля располагался под углом $45^{\circ}$ к лазерному излучению и оптической оси измерительной схемы. Изображение образца с помощью линзы проектировалось на спектральновременную щель размером $0.1 \times 0.2 \mathrm{~mm}$. Изображение щели при помощи линзы проектировалось на входную щель полихроматора, который разворачивал свечение в спектр в диапазоне $\lambda=350-750 \mathrm{~nm}$. С выхода полихроматора изображение спектра проектировалось на фотокатод электронно-оптического преобразователя (ЭОП) фотохронографа, работающего в режиме линейной развертки (стрик-камера). Светящаяся матрица на выходном экране ЭОП считывалась ПЗС-матрицей и передавалась на компьютер для дальнейшей обработки. По горизонтальным элементам матрицы можно построить кинетику свечения на фиксированной длине волны, по вертикальным элементам - спектр свечения в фиксированный момент времени. Для коррекции регистрируемого свечения на спектральную чувствительность электронно-оптического тракта применялся метод эталонной лампы [12].

Спектральное и временное разрешение задается размерами спектрально-временной щели. При размерах щели $0.1 \times 0.2 \mathrm{~mm}$ спектральное разрешение составляло $10 \mathrm{~nm}$, временное разрешение на коротких развертках фотохронографа может достигать $2 \mathrm{~ns}$. В настоящей работе применялась развертка $2.3 \mathrm{~ms}$, на которой временное разрешение составляло $2 \mu \mathrm{s}$, что много меньше длительности лазерного импульса $(120 \mu \mathrm{s})$.

\section{Результаты и обсуждения}

Для удобства представления результатов данной работы приведем таблицу порогов зажигания углей на различных стадиях, измеренных в работе [11].
Пороги зажигания углей на различных стадиях зажигания [11]

\begin{tabular}{c|c|c|c}
\hline Марка угля & $H_{c r}^{(1)}, \mathrm{J} / \mathrm{cm}^{2}$ & $H_{c r}^{(2)}, \mathrm{J} / \mathrm{cm}^{2}$ & $H_{c r}^{(3)}, \mathrm{J} / \mathrm{cm}^{2}$ \\
\hline ДГ & 0.39 & 1.60 & 2.40 \\
$\Gamma$ & 0.45 & 1.85 & 3.30 \\
Ж & 0.47 & 1.10 & 5.50 \\
$\mathrm{~K}$ & 0.35 & 0.90 & $6.50^{*}$
\end{tabular}

Примечание ${ }^{*}$ Приведено значение $H_{c r}^{(3)}$ для угля марки К, измеренное более точно, чем в [11].

На рис. 1-4 представлены спектры свечения поверхности образцов углей исследованных марок при воздействии лазерных импульсов с различными плотностями энергии, измеренные в момент воздействия лазерных импульсов.

В наших предыдущих работах [9-11] считалось, что при воздействии лазерных импульсов с плотностью энергии $H_{c r}^{(1)}$, которая соответствует порогу обнаружения свечения, должно наблюдаться свечение нагретой поверхности частиц угля, имеющее тепловой спектр. Кроме того, в спектры свечения, регистрируемые при $H_{c r}^{(1)}$, возможно, дает вклад свечение, связанное с зажиганием микровыступов на поверхности частиц угля, которое наблюдалось в работе [13]. Как видно из рис. $1, a-4, a$, спектры свечения при воздействии импульсов с плотностью энергии $H_{c r}^{(1)}$ не являются тепловыми. Более того, наблюдается различие в форме регистрируемых спектров (для конкретной марки угля) при воздействии лазерных импульсов с плотностью энергии, равной $H_{c r}^{(1)}$. Для объяснения этого результата сделаны микрофотографии всех марок углей на электронном сканирующем микроскопе JEOL JSM-6390 LV.

$\mathrm{Ha}$ рис. 5 для примера приведена типичная микрофотография угля марки Ж. Размеры СЭМмикрофотографии близки к размеру участка образца угля, свечение которого проектируется на спектральновременную щель электронно-оптической схемы регистрации. Как видно из рис. 5, в поле спектральновременной щели могут попадать как относительно крупные частицы угля, на поверхности которых имеются микровыступы, так и частицы угля микронных размеров. (Как отмечалось ранее, фракции частиц исследуемых углей имеют широкое распределение по размерам.) Анализ литературных данных $[6,13]$ и полученные экспериментальные результаты (рис. 5) позволяют сделать вывод, что свечение при воздействии на образцы угля с плотностью энергии $H_{c r}^{(1)}$ может быть связано с зажиганием микровыступов на поверхности относительно крупных частиц угля, реакционно активных к нагреву лазерным излучением. Кроме того, возможно воспламенение частиц угля размером порядка $\sim 1 \mu \mathrm{m}$. Таким образом, спектры свечения на рис. $1, a-4, a$ связаны с зажиганием микровыступов на поверхности крупных частиц угля и зажиганием мелких частиц угля размером 

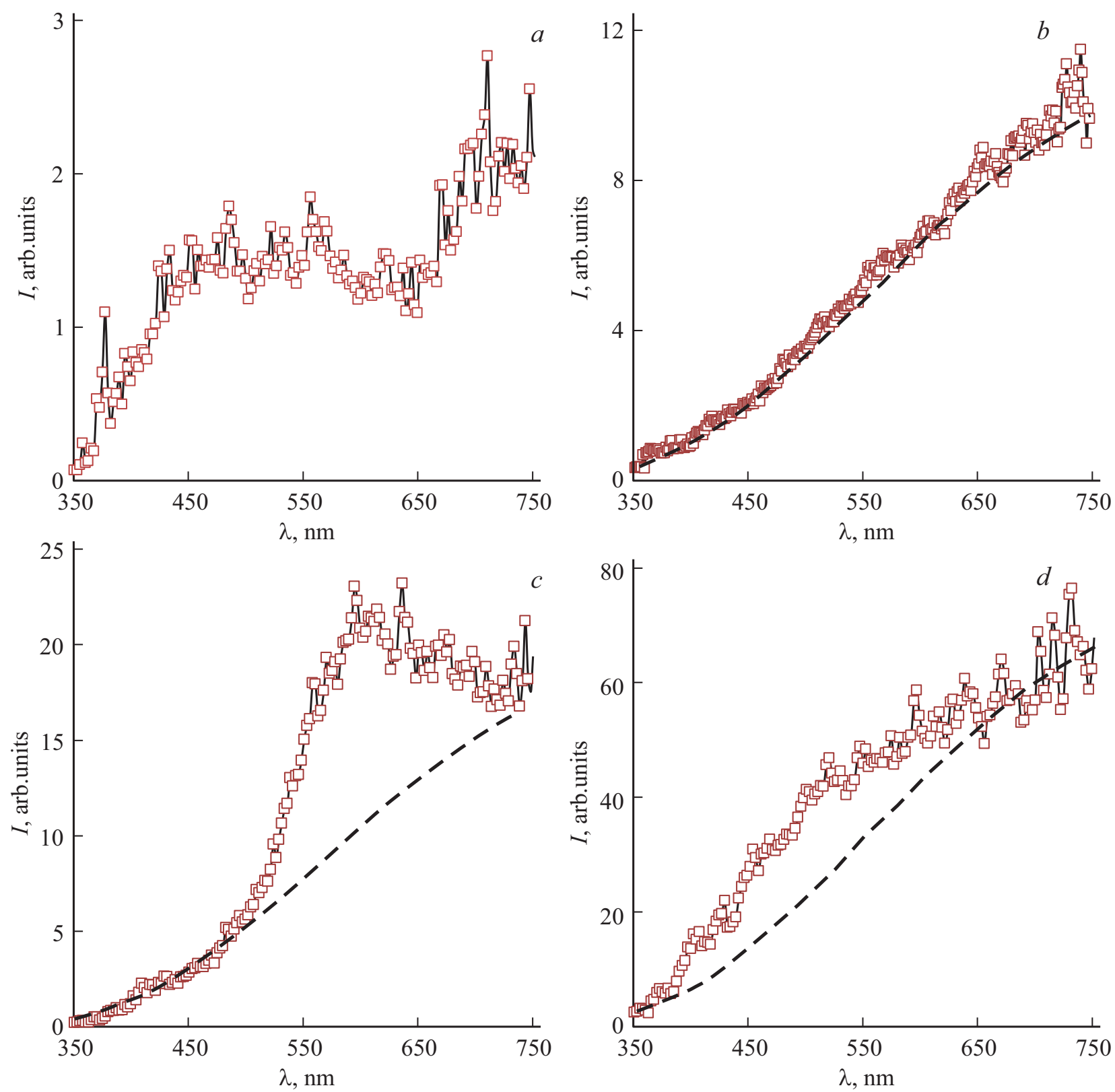

Рис. 1. Свечение поверхности угля марки ДГ при воздействии лазерных импульсов с различными плотностями энергии $H$. $a-$ $H_{c r}^{(1)}=0.39 \mathrm{~J} / \mathrm{cm}^{2}, b-H=1.00 \mathrm{~J} / \mathrm{cm}^{2}, c-H_{c r}^{(2)}=1.60 \mathrm{~J} / \mathrm{cm}^{2}, d-H_{c r}^{(3)}=2.40 \mathrm{~J} / \mathrm{cm}^{2}$.

порядка $\sim 1 \mu \mathrm{m}$. Сопоставление полученных спектров на рис. $1, a-4, a$ с табличными значениями молекулярных спектров $[14,15]$ позволяет сделать вывод, что в данном спектральном диапазоне свечение связано с воспламенением на воздухе окиси углерода $\left(2 \mathrm{CO}+\mathrm{O}_{2} \rightarrow 2 \mathrm{CO}_{2}\right)$ и свечением возбужденных молекул $\mathrm{H}_{2}$ и $\mathrm{H}_{2} \mathrm{O}$, аналогично идентифицированных в спектрах свечения летучих веществ при зажигании бурого угля на более поздних этапах горения ( $0.5 \mathrm{~ms})$ [10]. Таким образом, приходим к выводу, что нетепловая природа спектров объясняется регистрацией свечения продуктов окисления частиц угля и возбужденных молекул летучих веществ, образую- щихся при термическом разложении микровыступов на поверхности крупных частиц угля.

При увеличении плотности энергии лазерного импульса до значения, превышающего $H_{c r}^{(1)}$, но меньшего $H_{c r}^{(2)}$, интенсивность свечения возрастает (рис. $1, b-4, b$ ), спектры свечения приобретают тепловой характер. Эти результаты можно объяснить следующим образом. При увеличении плотности энергии лазерного импульса $H$ возрастает температура нагрева поверхности крупных частиц угля, что приводит к увеличению интенсивности теплового свечения. При этом вклад в свечение, связанный с зажиганием микрочастиц угля, дает небольшую 

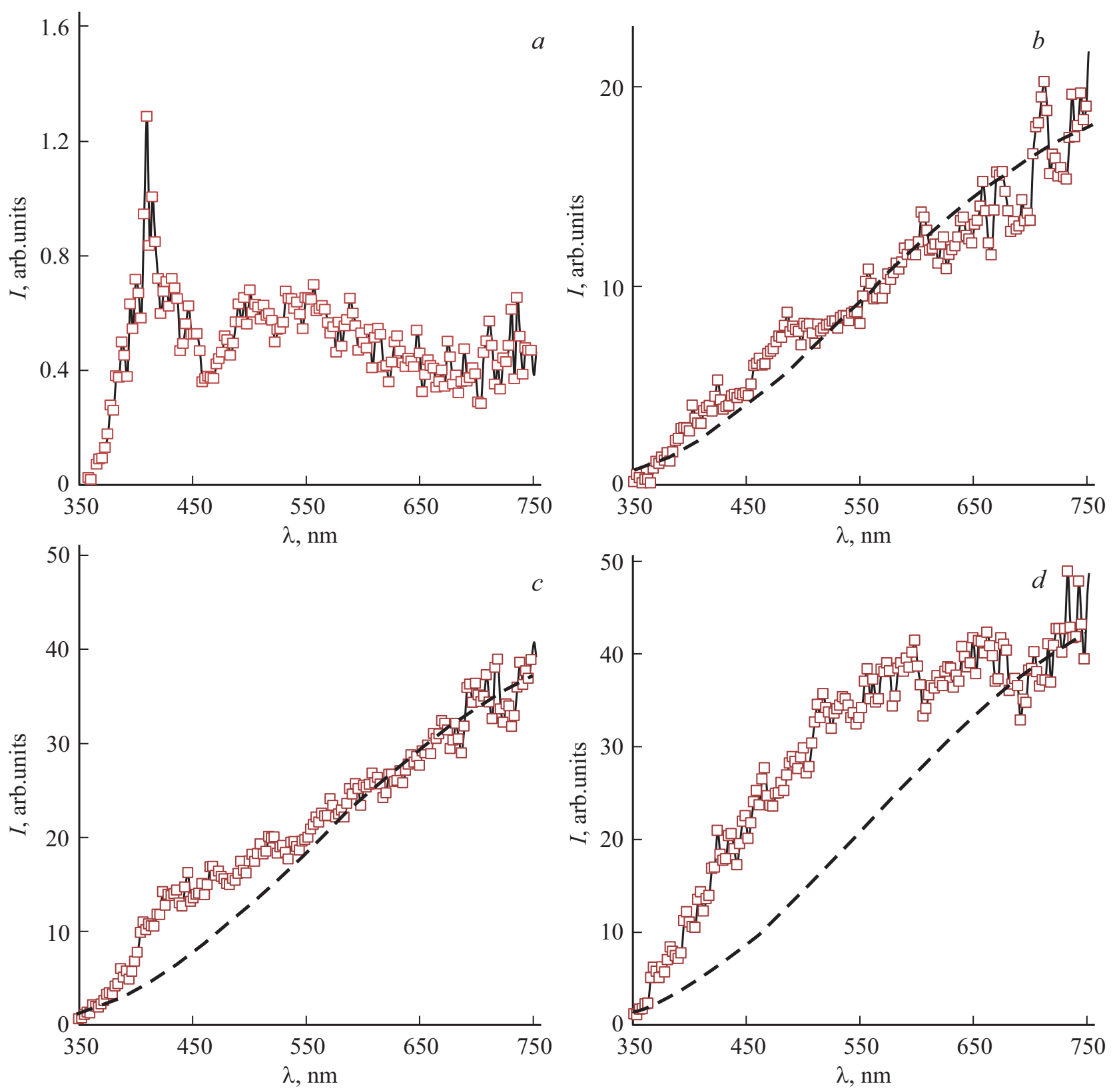

Рис. 2. Свечение поверхности угля марки Г при воздействии лазерных импульсов с различными плотностями энергии $H$. $a-$ $H_{c r}^{(1)}=0.45 \mathrm{~J} / \mathrm{cm}^{2}, b-H=1.00 \mathrm{~J} / \mathrm{cm}^{2}, c-H_{c r}^{(2)}=1.85 \mathrm{~J} / \mathrm{cm}^{2}, d-H_{c r}^{(3)}=3.30 \mathrm{~J} / \mathrm{cm}^{2}$.

погрешность, и спектры свечения имеют преимущественно тепловой характер. Спектры аппроксимируются формулой Планка при $T=3100 \mathrm{~K}$.

При достижении плотности энергии лазерного импульса значения, соответствующего $H_{c r}^{(2)}$ (рис. $\left.1, c-4, c\right)$, регистрируются неэлементарные спектры свечения, включающие тепловую составляющую, на которую накладывается свечение летучих веществ, образующиеся в результате воспламенения поверхности частицы угля. В предположении, что тепловая составляющая в спектрах на рис. $1, c-4, c$ имеет температуру, приблизительно равную температуре поверхности, соответствующей спектрам на рис. $1, b-4, b$, на рис. $1, c-4, c$ штрихами нанесены кривые, соответствующие тепловой составляющей свечения при $T=3100 \mathrm{~K}$. Последняя может быть обусловлена не только свечением поверхности частиц, но и раскаленными углеродными частицами, вылетающими с поверхности частиц угля. Последний вывод наиболее вероятен, поскольку при воздействии лазерного импульса с плотностью энергии $H_{c r}^{(2)}$ на образец угля появляется пламя высотой 3-4 mm. Если расположить стеклянную пластину на расстоянии $2 \mathrm{~mm}$ от поверхности образца угля, то при $H=H_{c r}^{(2)}$ на ней образуется черный налет, связанный с осаждением угле- 

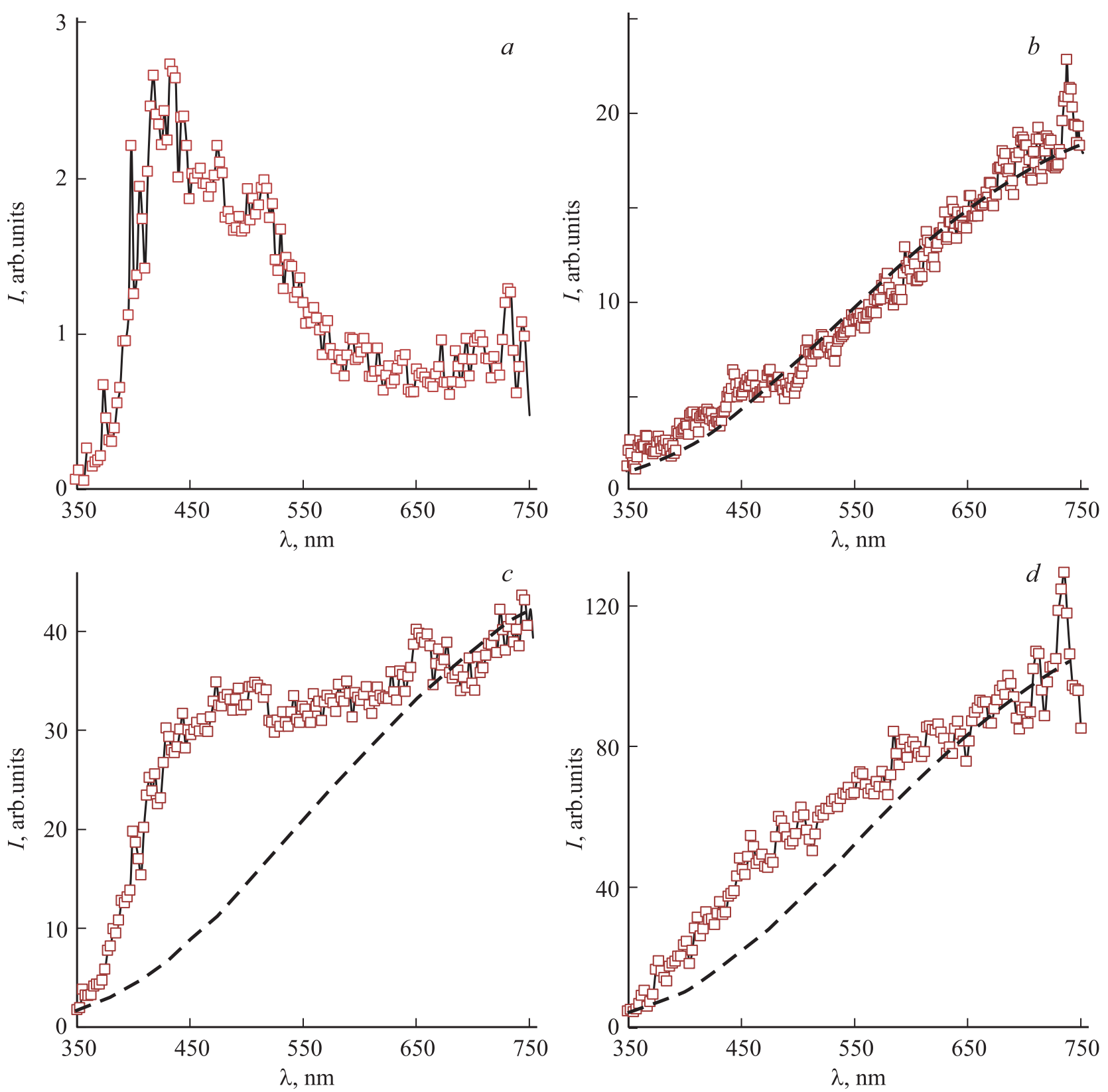

Рис. 3. Свечение поверхности угля марки Ж при воздействии лазерных импульсов с различными плотностями энергии $H$. $a-$ $H_{c r}^{(1)}=0.47 \mathrm{~J} / \mathrm{cm}^{2}, b-H=1.00 \mathrm{~J} / \mathrm{cm}^{2}, c-H_{c r}^{(2)}=1.10 \mathrm{~J} / \mathrm{cm}^{2}, d-H_{c r}^{(3)}=5.50 \mathrm{~J} / \mathrm{cm}^{2}$.

родных частиц, вылетающих с поверхности образца угля. Превышение интенсивности свечения над тепловой составляющей на рис. $1, c-4, c$ можно отнести к свечению летучих веществ, образующихся в результате зажигания поверхности образца угля.

Таким образом, можно сделать вывод, что при плотности энергии $H=H_{c r}^{(2)}$ уже во время лазерного импульса происходит воспламенение поверхности частиц угля с вылетом углеродных частиц, выходом и воспламенением летучих веществ, т. е. механизм горения гетерогенный.

При увеличении плотности энергии $H \geq H_{c r}^{(3)}$ спектры свечения во время воздействия лазерного импульса, представленные на рис. $1, d-4, d$, также имеют неэлементарный характер. Вид спектров позволяет предположить, что во время воздействия лазерного импульса протекают те же процессы, что и при плотности энергии $H_{c r}^{(2)}$, которые описаны выше. Поскольку все рисунки выполнены в одном масштабе, можно сделать вывод, что интенсивность свечения возрастает с ростом плотности энергии излучения $H$.

Отметим, что при плотности энергии лазерного импульса $H_{c r}^{(3)}$ в частицах угля развиваются изотермические химические реакции, которые приводят к зажиганию нелетучего остатка во временном масшта- 

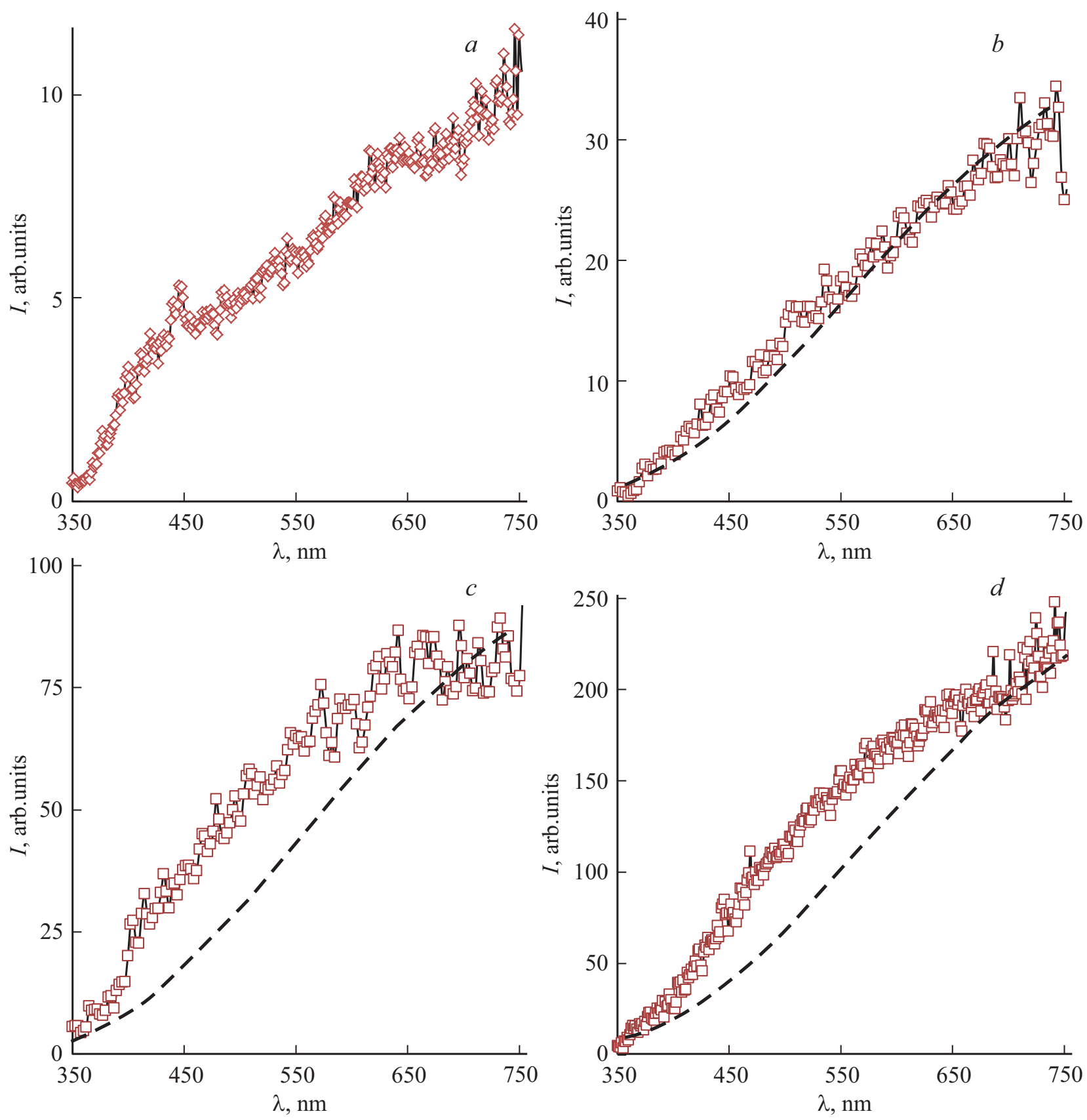

Рис. 4. Свечение поверхности угля марки К при воздействии лазерных импульсов с различными плотностями энергии $H . a-$ $H_{c r}^{(1)}=0.35 \mathrm{~J} / \mathrm{cm}^{2}, b-H=0.70 \mathrm{~J} / \mathrm{cm}^{2}, c-H_{c r}^{(2)}=0.90 \mathrm{~J} / \mathrm{cm}^{2}, d-H_{c r}^{(3)}=6.50 \mathrm{~J} / \mathrm{cm}^{2}$.

бе $\sim 50-100 \mathrm{~ms}[9-11]$. Однако исследование этого процесса в задачу данной работы не входило.

\section{Выводы}

1. Свечение, связанное с воздействием излучения на исследованные марки каменных углей с плотностью энергии, соответствующей значению $H_{c r}^{(1)}$, обусловлено зажиганием микровыступов на поверхности относительно крупных частиц угля и частиц угля микронных размеров, присутствующих во фракции. Спектры свечения связаны с продуктами окисления частиц угля и возбужденными молекулами летучих веществ, которые образуются при термическом разложении микровыступов на поверхности крупных частиц угля.

2. В диапазоне плотностей энергии лазерного излучения от $H_{c r}^{(1)}$ до $H_{c r}^{(2)}$ преобладает тепловое свечение поверхности относительно крупных частиц угля при $T=3100 \mathrm{~K}$.

3. При плотностях энергии $H>H_{c r}^{(2)}$ во время лазерного импульса происходит зажигание поверхности 


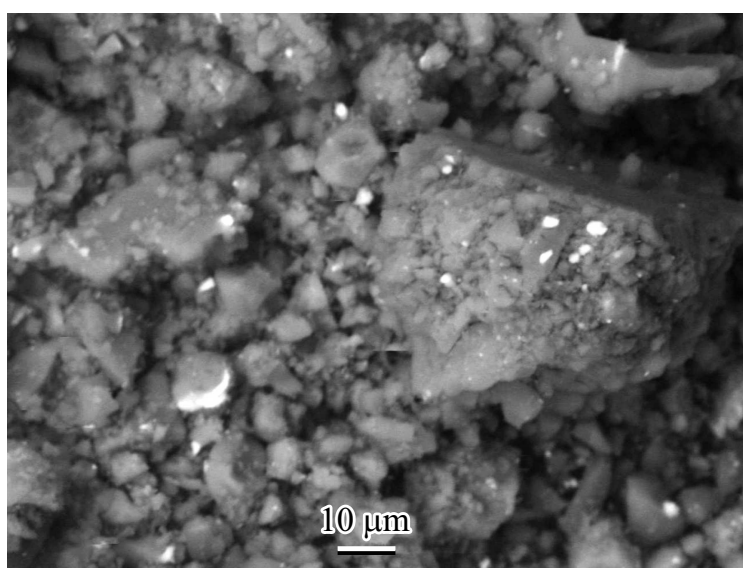

Рис. 5. Микрофотография участка образца угля марк Ж, сделанная на электронном микроскопе.

частиц угля. В спектры вносят вклады свечение вылетающих раскаленных углеродных частиц и свечение продуктов окисления летучих веществ, образующихся при термическом разложении поверхности образца угля.

4. При увеличении плотности энергии $H \geq H_{c r}^{(3)}$ во время лазерного импульса протекают процессы, описанные в п. 3, но с большей спектральной интенсивностью.

\section{Благодарности}

Авторы выражают благодарность А.Н. Заостровскому за предоставленные образцы углей, Н.И. Федоровой за проведение технического анализа образцов, С.А. Созинову за микрофотографию.

\section{Финансирование работы}

Работа выполнена в рамках гос. задания ИУХМ ФИЦ УУХ СО РАН (проект АААА-А17-117041910150-2) и при финансовой поддержке РФФИ в рамках научного проекта № 20-43-420019 р_а (подготовка и анализ образцов) на оборудовании ЦКП ФИЦ УУХ СО РАН.

\section{Конфликт интересов}

Авторы заявляют, что у них нет конфликта интересов.

\section{Список литературы}

[1] Chen J.C., Taniguchi M., Narato K., Ito K. // Combustion and Flame. 1994. V. 97. N 1. P. 107-117. doi 10.1016/00102180(94)90119-8

[2] Glova A.F., Lysikov A.Ju., Zverev M.M. // Quantum Electron. 2009. V. 39. N 6. P. 537-540. doi 10.1070/QE2009v039n06ABEH013906

[3] Taniguchi M., Kobayashi H., Kiyama K., Shimogori Y. // Fuel. 2009. V. 88. N 8. P. 1478-1484. doi 10.1016/j.fuel.2009.02.009

[4] Boiko V.M., Volan'skii P., Klimkin V.F. // Combust. Explos. Shock. Waves. 1981. V. 17. N 5. P. 545. doi 10.1007/BF00798143
[5] Phuoc T.X., Mathur M.P., Ekmann J.M. // Combustion and Flame. 1993. V. 93. N 1-2. P. 19-30. doi 10.1016/00102180(93)90081-D

[6] Погодаев В.А. // Физика горения и взрыва. 1984. Т. 20. B. 1. C. 51-55; Pogodaev V.A. // Combustion, Explosion, and Shock Waves. 1984. V. 20. N 1. P. 46-50.

[7] Kuzikovskii A.V., Pogodaev V.A. // Combust. Explos. Shock. Waves. 1977. V. 13. N 5. P. 666. doi 10.1007/BF00742231

[8] Phuoc T.X., Mathur M.P., Ekmann J.M. // Combustion and Flame. 1993. V. 94. N 4. P. 349-362. doi 10.1016/00102180(93)90119-Ng

[9] Адуев Б.П., Нурмухаметов Д.Р., Нелюбина Н.В., Ковалев Р.Ю., Заостровский А.Н., Исмагилов З.Р. // Химическая физика. 2016. Т. 35. В. 12. С. 47-47. doi 10.7868/S0207401X16120025; Aduev B.P., Nurmukhametov D.R., Nelyubina N.V., Kovalev R.Y., Ismagilov Z.R. // Russian J. Phys. Chem. B. 2016. V. 10. N 6. P. 963-965.

[10] Адуев Б.П., Нурмухаметов Д.Р., Ковалев Р.Ю., Крафбт Я.В., Заостровский А.Н., Гудилин А.В., Исмагилов 3.P. // Опт. и спектр. 2018. Т. 125. В. 2. C. 277-283. doi 10.21883/OS.2018.08.46373.29-18; Aduev B.P., Nurmukhametov D.R., Kovalev R.Y., Kraft Ya.V., Ismagilov Z.R. // Opt. Spectrosc. 2018. V. 125. N 2. P. 293-299.

[11] Адуев Б.П., Нурмухаметов Д.Р., Крафт Я.В., Исмагилов 3.P. // Опт. и спектр. 2020. Т. 128. В. 3. С. 442 448. doi 10.21883/OS.2020.03.49073.302-19; Aduev B.P., Nurmukhametov D.R., Kraft Ya.V., Ismagilov Z.R. // Opt. Spectrosc. 2020. V. 128. N 3. P. 429-435.

[12] Левшин Л.В., Салецкий А.М. Люминесценция и ее измерения. М.: МГУ, 1989; Levshin L.V., Saletskii A.M. Luminescence and Its Measurements. M.: Mosk. Gos. Univ., 1989.

[13] Yang Q., Peng Z. // Intern. J. Hydrogen Energy. 2010. V. 35. P. 4715-4722. doi 10.1016/j.jhydene.2009.12.045

[14] Гейдон $A$. Спектроскопия и теория горения. М: Изд-во ИЛ, 1950. 308 c.; Gaydon A. Spectroscopy and Combustion Theory. New York: Springer, 1942.

[15] Пирс Р., Гейдон А. Отождествление молекулярных спектров. М: Из-во ИЛ, 1949. 248 с.; Pearse R., Gaydon A. The Identification of Molecular Spectra. Netherlands: Springer, 1976. 